Proceedings of the International School and Conference on Optics and Optical Materials, ISCOM07, Belgrade, Serbia, September 3-7, 2007

\title{
Influence of Various Impurities on the Optical Properties of $\mathrm{YbF}_{3}$-Doped $\mathrm{CaF}_{2}$ Crystals
}

\author{
M. Stef*, A. Pruna, N. Pecingina-Garjoaba \\ AND I. NICOARA \\ Department of Physics, West University of Timisoara \\ Blvd. V. Parvan 4, Timisoara 300223, Romania
}

Calcium fluoride crystals doped with $\mathrm{YbF}_{3}$ and co-doped with $\mathrm{LiF}$ and $\mathrm{NaF}$ were grown using the vertical Bridgman method. Several of rare-earth ions (such as $\mathrm{Eu}, \mathrm{Sm}, \mathrm{Ho}, \mathrm{Tm}$, and $\mathrm{Yb}$ ) can be stabilized in the divalent state in the $\mathrm{CaF}_{2}$. The change of valence was attained by various methods. The optical absorption spectra reveal the characteristic absorption bands of the $\mathrm{Yb}^{3+}$ and $\mathrm{Yb}^{2+}$ ions. This means that the developed crystal growth process achieves a good $\mathrm{Yb}^{3+}$ to $\mathrm{Yb}^{2+}$ conversion in the as-grown crystals. The influence of other impurities, such as $\mathrm{Na}^{+}$or $\mathrm{Li}^{+}$, on the absorption and emission spectrum of $\mathrm{YbF}_{3}$-doped $\mathrm{CaF}_{2}$ was studied. The $\mathrm{Li}^{+}$and $\mathrm{Na}^{+}$ ions drastically decrease the absorption coefficient of the $\mathrm{Yb}^{2+}$ ions in the UV band and the emission intensity by excitation in $230 \mathrm{~nm}$.

PACS numbers: 52.25.Os, 76.30.Kg, 87.64.kv, 42.55.Rz

\section{Introduction}

Interest in rare-earth ( $\mathrm{RE}$ )-doped $\mathrm{CaF}_{2}$ crystals used as laser material is still growing due to the well known good optical characteristics of the $\mathrm{CaF}_{2}$ host. Several of RE ions (such as $\mathrm{Eu}, \mathrm{Sm}, \mathrm{Ho}, \mathrm{Tm}$, and $\mathrm{Yb}$ ) can be stabilized in the divalent state in the $\mathrm{CaF}_{2}$. The change of valence has been attained by various methods [1-5]. There are a few reported results [6-8] about the properties of the $\mathrm{Yb}^{2+}$-ions, with high concentration in the as-grown crystals. The $\mathrm{Yb}^{3+}$ ion properties have been intensively studied due to its strong IR luminescence that can be easily pumped with laser diodes. The properties of $\mathrm{Yb}^{2+}$ ions have been less investigated, mainly only for its intense and broad yellow-green $(535-560 \mathrm{~nm})$ luminescence [6-8]. The influence of monovalent ions (such as $\mathrm{Li}^{+}$and $\mathrm{Na}^{+}$) on

*corresponding author; e-mail: marius_stef2002@yahoo.com 
the absorption and emission spectra of the $\mathrm{YbF}_{3}$ doped $\mathrm{CaF}_{2}$ crystals has been less investigated, mainly on the properties of the $\mathrm{Yb}^{3+}$ ions [9].

The goal of this work is to investigate the influence of $\mathrm{Li}^{+}$and $\mathrm{Na}^{+}$ions on absorption and emission spectra of the divalent ytterbium ions in the as-grown $\mathrm{YbF}_{3}$-doped $\mathrm{CaF}_{2}$ crystals. Besides the reported yellow-green luminescence, new emission bands have been observed, not reported before, in the near UV spectral region.

\section{Experiment}

Pure, $\mathrm{YbF}_{3}$-doped and $\mathrm{LiF}$-, $\mathrm{NaF}$-codoped $\mathrm{CaF}_{2}$ crystals have been grown in our crystal research laboratory using vertical Bridgman method [10]. Suprapure grade (Merck) calcium fluoride, $\mathrm{YbF}_{3}, \mathrm{LiF}$ and $\mathrm{NaF}$ were used as the starting materials. Various two concentrations $\mathrm{YbF}_{3}: \mathrm{CaF}_{2}$ crystals have been obtained with $\mathrm{YbF}_{3}$ added to the melts in molar 0.7 and 1.2 concentrations and other $\mathrm{NaF}$ and $\mathrm{LiF}$-codoped $\mathrm{Yb}: \mathrm{CaF}_{2}$ crystals. The crystal growth process begins by lowering the crucible in the temperature distribution in the furnace. The pulling rate was $4 \mathrm{~mm} / \mathrm{h}$. To prevent the evaporation of the $\mathrm{NaF}$ and $\mathrm{LiF}$, a thin graphite lid was put on the charge in the crucible. Transparent colorless crystals of about $10 \mathrm{~mm}$ diameter over 6-7 m long were obtained in spectral pure graphite crucible in vacuum $\left(\approx 10^{-1} \mathrm{~Pa}\right)$ using a shaped graphite furnace [10]. The crystals have been cooled to room temperature using an established procedure. The optical absorption spectra reveal the characteristic UV absorption bands of the $\mathrm{Yb}^{2+}$ ions with more than ten times higher absorption coefficient than of the $\mathrm{Yb}^{3+}$ ions (see Fig. 1). This means that the developed crystal growth process achieves a good $\mathrm{Yb}^{3+}$ to $\mathrm{Yb}^{2+}$ conversion in the as-grown crystals. Room temperature optical absorption spectra were recorded by a Shimadzu 1650PC. The luminescence

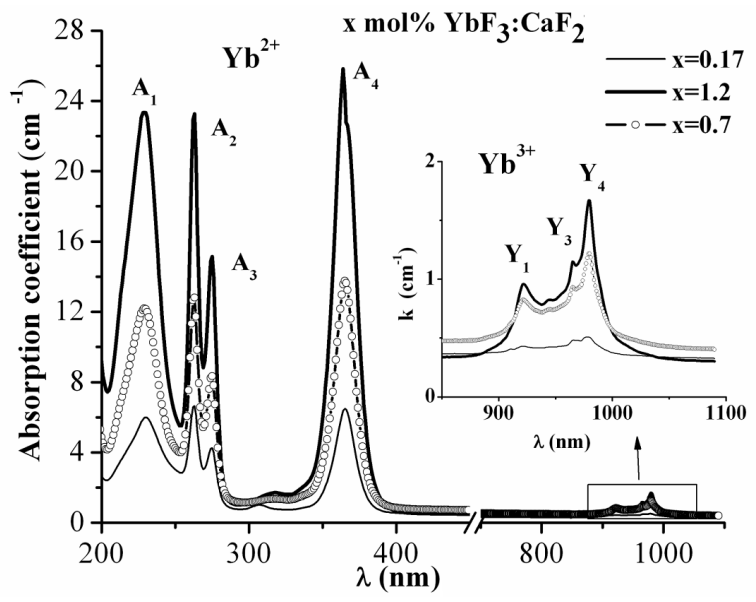

Fig. 1. Absorption spectra of $\mathrm{YbF}^{3}$-doped $\mathrm{CaF}_{2}$ crystals. The inset shows the absorption spectra of the trivalent ytterbium. Samples thickness varies between $2-2.6 \mathrm{~mm}$. 
measurements were carried out using a Perkin Elmer LS 55 Spectrofluorimeter in the National Institute for Materials Physics, Bucharest, Romania. All the measurements were recorded at room temperature. The studied samples have been cleaved from the obtained crystals and optically polished.

The mean objective of this work is to study the influence of the $\mathrm{Li}^{+}$and $\mathrm{Na}^{+}$ ions on the optical absorption and emission spectra of the $\mathrm{YbF}_{3}$ doped $\mathrm{CaF}_{2}$.

\section{Results and discussions}

When trivalent $\mathrm{RE}$ ions are incorporated in $\mathrm{CaF}_{2}$, lattice charge compensation is required to maintain the electrical neutrality of the system. The extra positive charge is usually compensated by interstitial fluorine ions $\left(\mathrm{F}_{\mathrm{i}}^{-}\right)$which can occupy various positions in the $\mathrm{CaF}_{2}$ lattice giving rise to various crystal field symmetries: the tetragonal $\left(C_{4 v}\right)$ symmetry in which $\mathrm{F}_{\mathrm{i}}^{-}$occupies a nearest-neighbor (NN) interstitial site, the trigonal $\left(C_{3 v}\right)$ symmetry, the rhombohedral $\left(C_{2 v}\right)$ or cluster configurations. Such a complicated structure leads in turn to optical transitions having the form of broad bands which can be used advantageously for production of broadly tunable solid-state lasers. In contrast with $\mathrm{Yb}^{3+}$-ions, divalent ytterbium ions do not need charge compensation and usually enter fluorite crystals in a cation substitutional position with cubic $\left(O_{h}\right)$ symmetry.

\subsection{Absorption spectra}

The absorption spectra of $\mathrm{YbF}_{3}$-doped crystals in the UV-VIS and near-IR region are shown in Fig. 1. The absorption spectra reveal the existence of both $\mathrm{Yb}^{2+}$ (in the near-UV) and $\mathrm{Yb}^{3+}$ ions in near-IR domain. The $\mathrm{Yb}^{3+}$ ions broad absorption spectrum is due to the spin-allowed ${ }^{2} F_{7 / 2} \rightarrow{ }^{2} F_{5 / 2}$ transition. The structure of the $\mathrm{Yb}^{3+}$ band is due to the crystal-field split, field with various symmetries, generated by several types of charge compensation. For $\mathrm{Yb}^{3+}$ ions the strongest absorption band peak appears around $Y_{4}=979 \mathrm{~nm}$ and corresponds to $C_{2 v}$ or $C_{3 v}$ symmetries. The other peaks, called $Y_{1}, Y_{2}$, and $Y_{3}$ bands, are also observed by several investigators, but there are some discrepancies between their spectra [1-4]. The sharp $Y_{1}=922 \mathrm{~nm}$ band has not been reported by [4] but has been observed by $[3,9,11]$. The intensity of the $Y_{2}=946 \mathrm{~nm}$ increases as the concentration increases. The $Y_{3}=964 \mathrm{~nm}$ band corresponds to transition of tetragonal $C_{4 v}$ site. All the absorption peaks increase as the $\mathrm{YbF}_{3}$ concentration increases.

The absorption spectrum of the $\mathrm{Yb}^{2+}$ ions is characterized by four strong absorption bands in UV domain peaked at $A_{1}=230 \mathrm{~nm}, A_{2}=263 \mathrm{~nm}, A_{3}=$ $275 \mathrm{~nm}, A_{4}=365 \mathrm{~nm}$. These bands are consistent with other reported experiments and calculations $[1,3,4,6-9,12]$. The UV region absorptions can be related to the $4 f^{14}-4 f^{13} 5 d$ transitions of the $\mathrm{Yb}^{2+}$ ions $[1,3,6,12]$. Absorption bands at $A_{1}, A_{2}$, and $A_{4}$ are assigned as transitions of isolated $\mathrm{Yb}^{2+}$ ions and the $A_{3}$ band as transition of $\mathrm{Yb}^{2+}$ ions surrounded by $\mathrm{Yb}^{3+}$ ions. As we can observe in Fig. 1, 
the increase in the concentration results in two distinct features: a broadening of the peaks and an increase in the absorption intensities.

Influence of the $\mathrm{Li}^{+}$and $\mathrm{Na}^{+}$ions. Figure 2 shows the absorption spectra of two $\mathrm{YbF}_{3}$ doped $\mathrm{CaF}_{2}$ crystals and Li- and $\mathrm{Na}$-codoped $\mathrm{Yb}: \mathrm{CaF}_{2}$ crystals.

The influence of the $\mathrm{Li}^{+}$and $\mathrm{Na}^{+}$ions on the absorption spectra is clear: both ions diminish drastically the $\mathrm{Yb}^{3+} \rightarrow \mathrm{Yb}^{2+}$ conversion in the as-grown crystals. The absorption intensity decreases more for the $\mathrm{Yb}, \mathrm{Na}: \mathrm{CaF}_{2}$ crystals than for the $\mathrm{Yb}, \mathrm{Li}: \mathrm{CaF}_{2}$ samples (Fig. 2b). The alkaline metal ions work as charge compensator and the sites of $\mathrm{Yb}^{3+}$ ions are probably predominantly $C_{2 v}$, in which $\mathrm{Na}^{+}$or $\mathrm{Li}^{+}$substitutes one of the eight nearest neighbor $\mathrm{Ca}^{2+}$ ions along any [110] direction. These structures are probably unfavorable for charge conversion during the growth process. The $\mathrm{Li}^{+}$and $\mathrm{Na}^{+}$ions do not affect the shape of the IR $\mathrm{Yb}^{3+}$ absorption spectra. The $\mathrm{Li}^{+}$ion decreases the absorption intensity in contrast with $\mathrm{Na}^{+}$ion which increases the intensity of the absorption peaks.
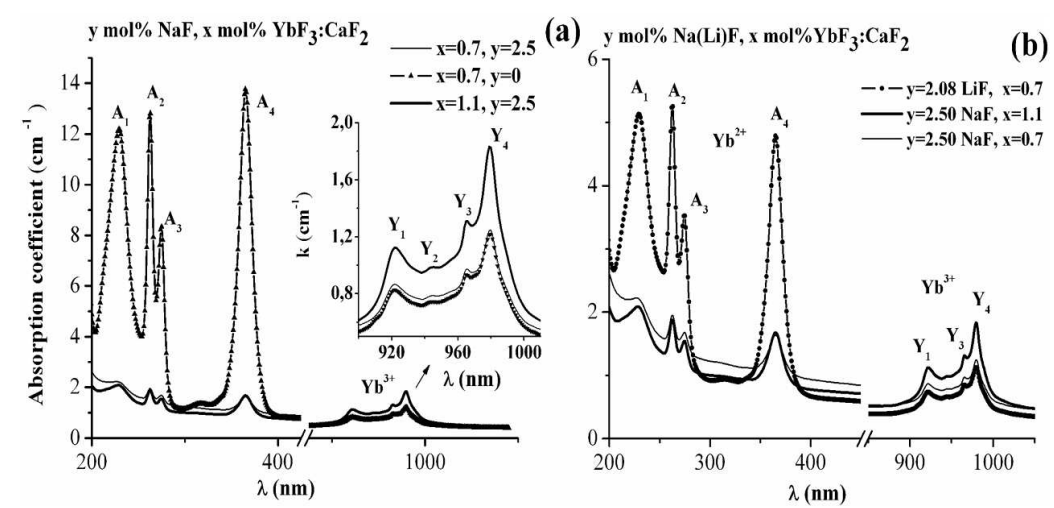

Fig. 2. Influence of $\mathrm{Li}^{+}$and $\mathrm{Na}^{+}$ions on the absorption spectra of the $\mathrm{YbF}_{3}: \mathrm{CaF}_{2}$ crystals.

\subsection{Emission spectra}

The room temperature emission spectra of 0.7 mol\% $\mathrm{YbF}_{3}: \mathrm{CaF}_{2}, \quad 1.1$ $\mathrm{mol} \% \mathrm{YbF}_{3}: \mathrm{CaF}_{2}$ samples and codoped with $\mathrm{NaF}$ and LiF excited with the $230 \mathrm{~nm}$ wavelength are shown in Fig. 3. The emission spectra of these crystals consist of two bands, one in the visible spectral domain, denoted I band, corresponding to the well known yellow-green emission [6-8], red-shifted for our samples, and one other broad band in the near UV-domain (300-400 nm), II band, consisting in some subbands. The emission bands of the $\mathrm{Yb}, \mathrm{Li}(\mathrm{Na}): \mathrm{CaF}_{2}$ samples are weaker than of the $\mathrm{YbF}_{3}$-doped samples. The strongest peak for both $\mathrm{YbF}_{3}$ doped $\mathrm{CaF}_{2}$ crystals is at $338 \mathrm{~nm}$; as the $\mathrm{YbF}_{3}$ concentration increases the intensity of the emission band decreases. The $\mathrm{Na}^{+}$and $\mathrm{Li}^{+}$ions do not affect the shape of II band. As the $\mathrm{YbF}_{3}$ concentration increases the $\mathrm{Na}^{+}$change the emission peaks. 
This shows a strong dependence of the emission on the concentration. This broad emission band has not been reported before.
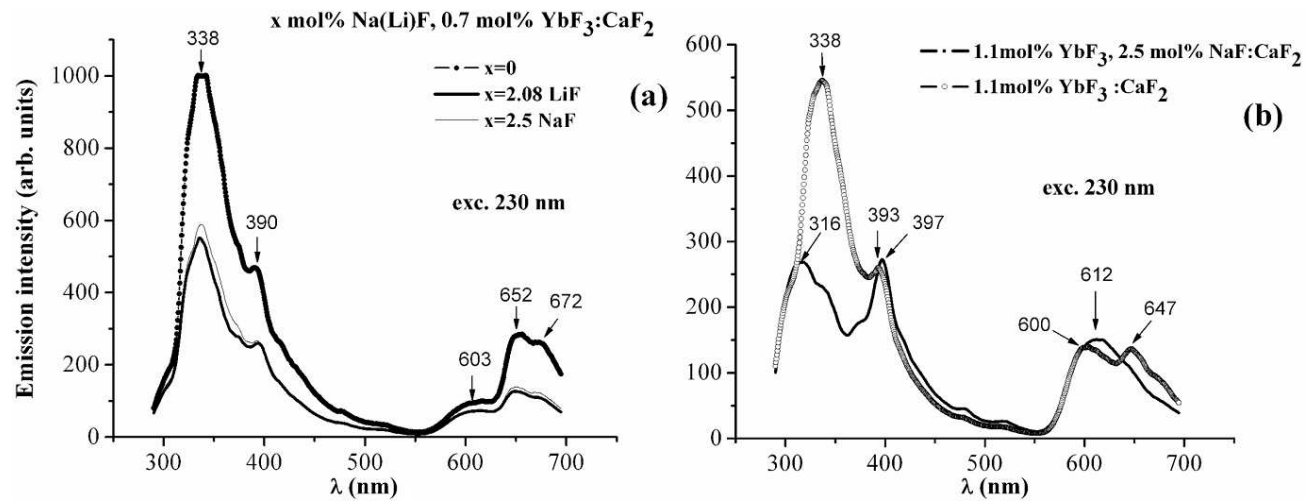

Fig. 3. Room temperature emission spectra of $\mathrm{Li}, \mathrm{Na}$-codoped $\mathrm{Yb}: \mathrm{CaF}_{2}$ crystals excited by $230 \mathrm{~nm}$.

Small shifts in the positions of the emission lines in I band occur for the two different $\mathrm{YbF}_{3}$ concentration samples. These emission lines of this band are red-shifted in comparison with the reported yellow-green luminescence [6-8]. The overlapping between emission and absorption spectra is weak, indicating that the crystals may have high quantum efficiency during the laser operation.

\section{Conclusions}

Various $\mathrm{YbF}_{3}$ concentration and NaF-, LiF-codoped $\mathrm{CaF}_{2}$ crystals have been grown using the conventional Bridgman technique. Room temperature optical absorption and emission spectra have been recorded in order to study the properties of the crystals. The $\mathrm{Li}^{+}$and $\mathrm{Na}^{+}$ions drastically decrease the absorption intensity of the characteristic UV peaks of $\mathrm{Yb}^{2+}$ ions. The luminescence studies reveal a strong concentration and codopant dependence of the emission bands by excitation in $230 \mathrm{~nm}$. Besides the reported yellow-green luminescence, red-shifted for our samples, one broad emission band has been observed in the near UV spectral region with a peak at $338 \mathrm{~nm}$, not reported before. Stabilized and high concentration divalent $\mathrm{Yb}$ ions in $\mathrm{CaF}_{2}$ host should be a good near UV laser material.

\section{Acknowledgments}

This work was financially supported by the Science Research Council, Romania, grant CEEX, no. 72/3758/2006. The authors would like to express their gratitude to Mr. I. Sarbu for help of the crystal growth process. 


\section{References}

[1] D.S. McClure, Z. Kiss, J. Chem. Phys. 39, 3251 (1963).

[2] J.R. O'Connor, H.A. Bostick, J. Appl. Phys. 33, 1868 (1962).

[3] S.M. Kaczmarek, T. Tsuboi, M. Ito, G. Boulon, G. Leniec, J. Phys., Condens. Matter 17, 3771 (2005).

[4] J. Kirton, S.D. McLaughlan, Phys. Rev. 155, 279 (1967).

[5] F.K. Fong, J. Chem. Phys. 41, 2291 (1964).

[6] P.P. Feofilov, Opt. Spectrosc. 1, 992 (1956).

[7] A.A. Kaplyanskii, P.P. Feofilov, Opt. Spectrosc. 13, 235 (1962).

[8] A.A. Kaplyanskii, V.N. Medvedev, P.L. Smolyanskii, Opt. Spectrosc. 41, 1043 (1976).

[9] L. Su, J. Xu, H. Li, L. Wei, W. Yang, Z. Zhao, J. Si, Y. Dong, G. Zhou, J. Cryst. Growth 277, 264 (2005).

[10] D. Nicoara, I. Nicoara, Mater. Sci. Eng. A 102, L1 (1988).

[11] W. Low, J. Chem. Phys. 37, 30 (1962).

[12] M.V. Eremin, Opt. Spectrosc. 29, 100 (1970). 